\title{
Comunicação
}

\section{Efeito de extratos proteicos de amendoim sobre o desenvolvimento, a capacidade infectiva e atividade de enzimas proteolíticas de Meloidogyne enterolobii ${ }^{1}$}

\author{
Juliana Martins Ribeiro ${ }^{2}$, José Mauro da Cunha e Castro ${ }^{3}$, Natoniel Franklin de Melo ${ }^{4}$ \\ Kátia Valevski Sales Fernandes ${ }^{5}$, Márcio dos Santos Teixeira Pinto ${ }^{6}$
}

\section{RESUMO}

No Brasil, Meloidogyne enterolobii vem causando perdas significativas na produção de goiabeiras e, no submédio do Vale do São Francisco, por exemplo, o impacto negativo decorrente da infecção e morte de goiabeiras tem refletido diretamente na qualidade de vida dos agricultores. Até o momento, não existem métodos de controle efetivos: os nematicidas avaliados experimentalmente não têm sido eficientes e não há produtos registrados no Ministério da Agricultura, Pecuária e Abastecimento para aplicação em goiabeiras. Assim, há necessidade de realizar pesquisa básica nesta área. A prospecção de proteínas relacionadas com a resistência em espécies resistentes pode ser uma alternativa para o desenvolvimento de medidas para seu controle. Para isso, foram realizados ensaios biológicos de toxicidade para a análise do efeito de extratos proteicos de amendoim sobre o desenvolvimento, a capacidade infectiva e atividade de enzimas proteolíticas de $M$. enterolobii visando à identificação de proteínas com potencial para controle desse nematoide. Os resultados obtidos indicaram que o extrato proteico total de amostras de raízes de plantas de amendoim inoculadas não tem efeito sobre as três características supracitadas. Sendo assim, são necessários estudos dessa natureza com outras espécies resistentes ao patógeno visando à identificação de proteínas que apresentem potencial para o seu controle.

Palavras chave: Arachis hypogaea, nematoide-das-galhas, proteínas de defesa.

\section{ABSTRACT \\ Effect of peanut protein extracts on the development, infective capacity and activity of proteolytic enzymes of Meloidogyne enterolobii}

In several regions of the country, including the São Francisco Valley, Meloidogyne enterolobii has caused significant losses in the production of guava, reflecting negatively on life quality of farmers in the region. To date, there is no effective control method, nematicides have been evaluated experimentally and have not been efficient in their control and there are no products registered with the Ministry of Agriculture, Livestock and Supply for use in guava. Therefore, there is a critical need for basic research on this area and the prospection of proteins related to resistance to $M$. enterolobii in nematode resistant species may be an alternative for the development of control measures. For this purpose, biological assays of toxicity were performed to analyze the effect of peanut protein extracts on the development,

\footnotetext{
Recebido para publicação em 27/03/2013 e aprovado em 04/09/2013.

${ }^{1}$ Trabalho financiado pela FACEPE, CNPq e Embrapa Semiárido.

${ }^{2}$ Bióloga, Doutora. Laboratório de Biotecnologia Vegetal, Embrapa Semiárido, BR 428, Km 152, Caixa Postal 23, Zona Rural, 56302-970, Petrolina, Pernambuco, Brasil. juliana.ribeiro@embrapa.br (autora para correspondência).

${ }^{3}$ Engenheiro-Agrônomo, Doutor. Laboratório de Nematologia, Embrapa Semiárido, BR 428, Km 152, Caixa Postal 23, Zona Rural, 56302-970, Petrolina, Pernambuco, Brasil. mauro.castro@embrapa.br

${ }^{4}$ Biólogo, Doutor. Laboratório de Biotecnologia Vegetal, Embrapa Semiárido, BR 428, Km 152, Caixa Postal 23, Zona Rural, 56302-970, Petrolina, Pernambuco, Brasil. natoniel.melo@embrapa.br

${ }^{5}$ Bióloga, Doutora. Laboratório de Química e Função de Proteínas e Peptídeos, Universidade Estadual do Norte Fluminense Darcy Ribeiro, Campus dos Goytacazes, Avenida Alberto Lamego, 2000, Parque Califórnia, 28013-602, Campos dos Goytacazes, Rio de Janeiro, Brasil. cowpkat@uenf.br

${ }^{6}$ Biólogo, Doutor. Faculdade de Medicina, Universidade Federal do Rio de Janeiro, Campus Macaé - Professor Aloísio Teixeira, Avenida São José do Barreto, s/n, São José do Barreto, 27965-045, Macaé, Rio de Janeiro, Brasil. marciostp@yahoo.com.br
} 
infective capacity and activity of proteolytic enzymes of $M$. enterolobii for the identification of proteins with potential to control this pest. Results showed that total protein extracts from peanut root samples inoculated with $M$. enterolobii has no effect on the three characteristics evaluated. Thus, similar studies with other species resistant to the pathogen are needed to identify proteins with potential to control M. enterolobii.

Key words: Arachis hypogaea, root-knot nematode, defense proteins.

\section{INTRODUÇÃO}

O manejo de áreas infestadas com nematoides é feito, em geral, com base nos métodos químico, genético e cultural. Até o momento, não existem métodos efetivos de controle, e o potencial de disseminação dessa praga por meio de mudas contaminadas e implementos agrícolas é elevado. No Brasil, ainda não há nematicidas registrados para utilização na cultura da goiabeira (Carneiro et al., 2001). Porta-enxertos e cultivares resistentes ainda não foram identificados. Algumas espécies de araçazeiro (Psidium cattleyanum L.) demonstraram resistência ao nematoide (Almeida et al., 2009), mas não apresentaram compatibilidade de enxertia com goiabeiras, inviabilizando o uso como porta-enxertos. A rotação de culturas, apesar de eficiente e bem difundida para o controle de várias doenças e pragas em culturas anuais (Good, 1968; Noe, 1998; Halbrendt \& LaMondia, 2004), não se aplica a espécies perenes como a goiabeira.

Frente às dificuldades encontradas, a prospecção de proteínas relacionadas com a resistência em espécies resistentes ao nematoide pode ser uma alternativa para o desenvolvimento de medidas de controle de $M$. enterolobii. O amendoim (Arachis hypogaea L.), utilizado para manejo de áreas contaminadas devido à resistência que apresenta a $M$. enterolobii, possui potencial biotecnológico para o estudo de fatores relacionados com a resistência ao nematoide. Assim, objetivou-se realizar ensaios biológicos de toxicidade para a análise do efeito de extratos proteicos de amendoim sobre o desenvolvimento, a capacidade infectiva e atividade de enzimas proteolíticas, visando à identificação de proteínas com potencial para controle de M. enterolobii.

\section{MATERIAL E MÉTODOS}

As proteínas totais foram extraídas de caules e raízes das plantas de amendoim, conforme metodologia estabelecida por Ribeiro et al. (2012), quantificadas pelo método de Bradford (1976), e o seu perfil foi analisado por eletroforese em gel de poliacrilamida em condições semidesnaturantes e desnaturantes (Laemmli, 1970).

O extrato proteico bruto da fração solúvel foi submetido à precipitação com sulfato de amônio até uma concen- tração de saturação de 10\%. Em seguida, o material foi estocado a $4{ }^{\circ} \mathrm{C}$ por uma noite, a fim de otimizar a precipitação. Após essa etapa, o material foi centrifugado a $10.000 \mathrm{~g}$ por 30 minutos, a $4{ }^{\circ} \mathrm{C}$. O sedimento foi definido como fração 0 -10 e estocado $\mathrm{a}-20^{\circ} \mathrm{C}$. O sobrenadante foi reprecipitado com sulfato de amônio até uma saturação de $60 \%$; o procedimento de centrifugação foi repetido; o sedimento obtido foi definido como fração 10 - 60; e o sobrenadante, definido como fração de sobrenadante final (SF). As frações obtidas foram dessalinisadas por diálise, liofilisadas, dosadas quanto à presença de proteínas e submetidas a análises de eletroforese (Laemmli, 1970).

A partir das massas de ovos formadas em galhas nas raízes de goiabeiras, juvenis de segundo estádio (J2) de M. enterolobii (Me) foram obtidos (Coolen e D'Herde, 1972; Baermann, 1917). A primeira coleta de J2 foi feita 24 horas após a montagem do funil e descartada. Após a segunda e terceira coletas, os $\mathrm{J} 2$ foram quantificados e usados em experimentos de toxicidade e eficiência infectiva de nematoides.

A eletroforese semidesnaturante em gel de poliacrilamida com gelatina (SDS-PAGE-Gelatina) foi realizada, e a revelação da atividade proteica consistiu no aparecimento de bandas brancas em um fundo azul (Tunga et al., 2003).

Para a realização do ensaio de toxicidade em uma placa de cultura (tipo ELISA) foram adicionados $20 \mu \mathrm{L}$ de extrato de raízes, ou fração de precipitação com sulfato de amônio, conforme supracitado. Em seguida, um volume de $50 \mu \mathrm{L}$ de suspensão com aproximadamente $50 \mathrm{~J} 2$ foi adicionado em cada poço. Finalizando, um volume de 130 $\mu \mathrm{L}$ de PBS (tampão fosfato $10 \mathrm{mM}$ ) foi adicionado, completando um volume de $200 \mu \mathrm{L}$. O tratamento correspondente ao controle foi efetuado adicionando-se apenas 20 $\mu \mathrm{L}$ de PBS em vez de extrato. O material foi incubado a 25 ${ }^{\circ} \mathrm{C}$ por 24 horas. Após esse período, os nematoides imóveis foram estimulados ao movimento por meio do toque de um fio fino e os que permaneceram imóveis foram considerados mortos. Os tratamentos adotados foram: T1: Controle (tampão fosfato $10 \mathrm{mM}, \mathrm{pH}$ 7,0); T2: Extrato proteico de raízes de amendoim - EPRA; T3: EPRA inoculadas com Me; T4: EPRA inoculadas com Me (fração 0 - 10); T5: EPRA inoculadas com Me (fração 10 - 60); e T6: EPRA inoculadas com Me (sobrenadante final). O ex- 
perimento foi conduzido em delineamento experimental inteiramente casualizado, com oito repetições. Os dados foram submetidos à análise de variância e ao teste de Tukey a $5 \%$ de probabilidade.

$\mathrm{O}$ ensaio de teste de eficiência infectiva foi realizado utilizando-se $\mathrm{J} 2$ após terem sido tratados com o mesmo procedimento descrito para o ensaio de toxicidade. Para isso, $50 \mathrm{~J} 2$ obtidos conforme descrito anteriormente foram inoculados em mudas de tomateiro com uma semana de idade. Após o período de 30 dias, foi contado o número de galhas por planta. O valor obtido foi comparado com os de plantas controle, em que os nematoides foram inoculados somente com tampão PBS. Os tratamentos e o delineamento experimental foram os mesmos supracitados.

\section{RESULTADOS E DISCUSSÃO}

Observou-se aumento significativo de uma proteína de aproximadamente $28 \mathrm{kDa}$ apenas em amostras de raízes inoculadas com $M$ enterolobii, e proteína diferencialmente expressa foi sequenciada e identificada como sendo uma lectina de ligação manose/glicose (Ribeiro et al., 2012). A amostra que apresentou a proteína diferencialmente expressa foi precipitada com sulfato de amônio para a elucidação de proteínas presentes em raízes de amendoim (Figura 1A). Também foi investigada a presença de inibidores de proteinases em extrato de raiz de amendoim e o seu efeito sobre proteases do extrato proteico de nematoides (Figura 1B).

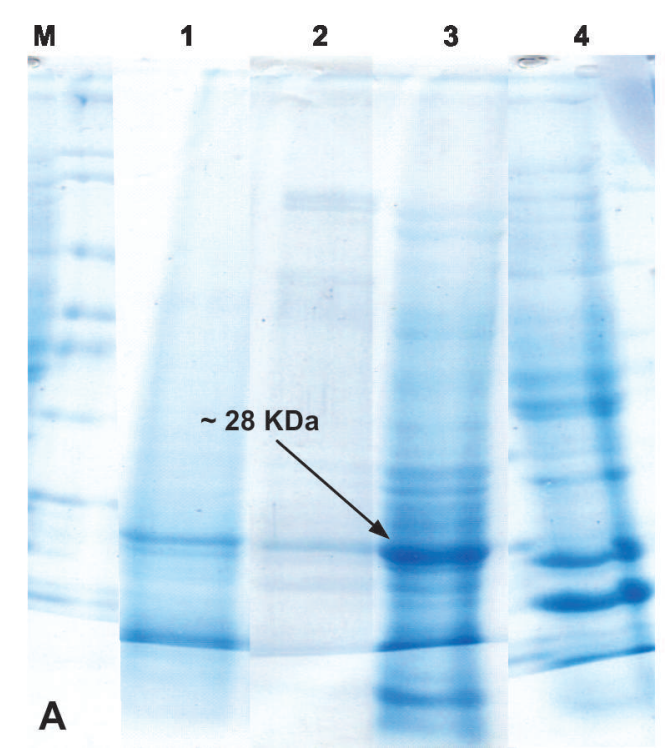

Os resultados revelaram que proteases de amendoim foram inibidas pelo extrato de nematoides (Figura 1B, linha 4, seta azul). Esse resultado evidencia a presença de inibidores de proteinases no extrato de nematoide agindo em enzimas do extrato de amendoim, ao contrário do que foi observado por Bellafiore et al. (2008), que evidenciaram o papel inibitório de cistatinas de Meloidogyne spp. na ação de proteases de tomateiro, espécie suscetível ao nematoide. No presente estudo, proteases de amendoim, planta resistente a $M$. enterolobii, foram inibidas pelo extrato proteico do nematoide, contrariando o esperado e necessitando de novos estudos para a elucidação desse fenômeno.

O ensaio de toxicidade não revelou diferença estatística entre o controle, o tratamento contendo apenas extrato proteico de raízes de amendoim e o de extrato proteico de raízes de amendoim inoculadas com $M$. enterolobii. Entretanto, quando a comparação foi realizada entre as diferentes frações proteicas precipitadas com sulfato de amônio, observou-se que a fração de 10 - 60 (T5) resultou em maior mortalidade do patógeno se comparado às frações de 0 - 10 (T4) e ao SF (T6). Na Figura 1, a fração de 10 - 60 corresponde àquela em que foi observado o aumento de uma proteína com cerca de $28 \mathrm{kDa}$. (Figura 2).

$\mathrm{O}$ teste de eficiência infectiva não revelou diferença estatística entre o controle, o tratamento contendo apenas extrato proteico de raízes de amendoim, aquele com extrato proteico de raízes de amendoim inoculadas com o

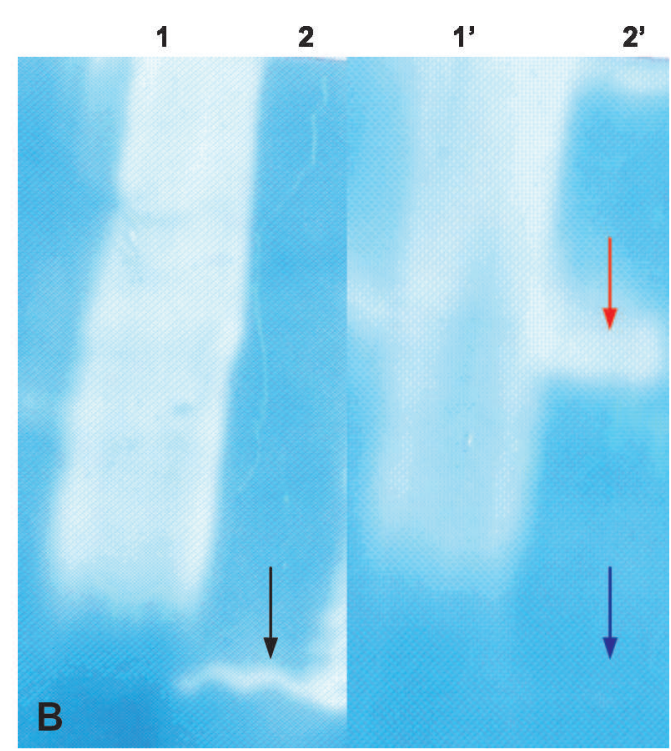

Figura 1. A: SDS - PAGE das frações proteicas obtidas por precipitação com sulfato de amônio do extrato total de raízes de amendoim inoculadas com Meloidogyne enterolobii.1: Extrato total; 2: Fração 0 - 10; 3: Fração 10 - 60; e 4: Sobrenadante final - SF. B: Atividade de enzimas proteolíticas das frações 10 - 60 (1) e SF (2). As mesmas frações citadas em 1 e 2, adicionadas de juvenis de segundo estádio de M. enterolobii (1' e 2'). Seta preta - atividade de uma protease presente na da fração SF de extratos proteicos de raízes de amendoim. Seta vermelha - atividade de uma protease presente na fração SF de extratos proteicos de M. enterolobii. Seta azul - inibição total da protease indicada pela seta preta na linha 2, promovida pelo extrato proteico do nematoide. 


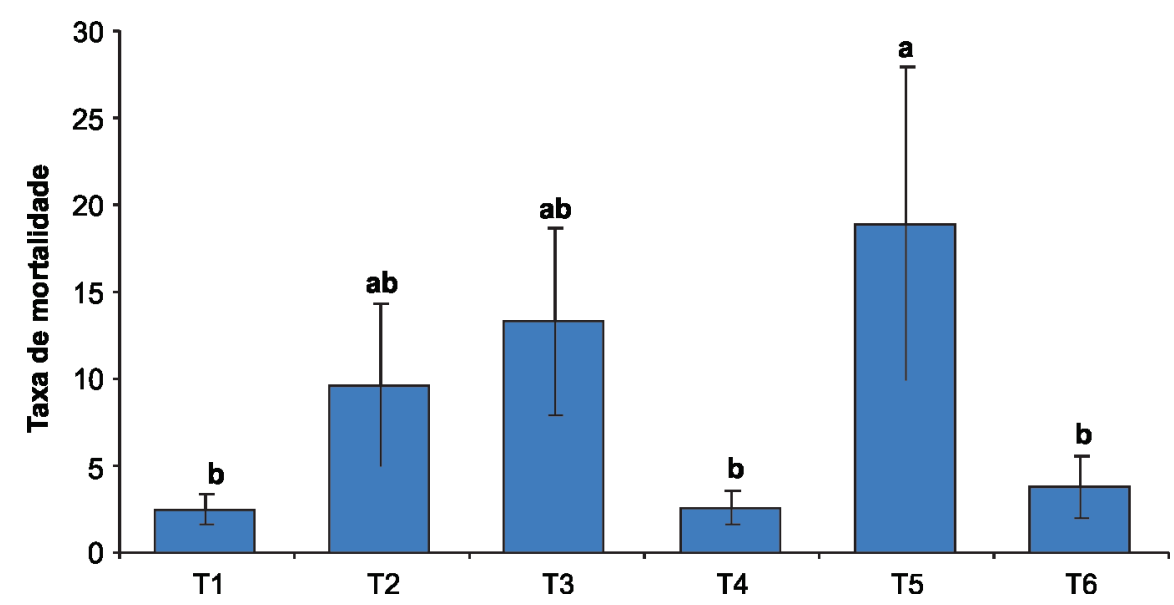

Figura 2. Taxa de mortalidade de nematoides nos tratamentos. T1: Controle (tampão fosfato $10 \mathrm{mM}, \mathrm{pH}$ 7,0); T2: Extrato proteico de raízes de amendoim - EPRA; T3: EPRA inoculadas com Me; T4: EPRA inoculadas com Me (fração 0 - 10); T5: EPRA inoculadas com Me (fração 10 - 60); e T6: EPRA inoculadas com Me (sobrenadante final).

nematoide e as diferentes frações proteicas $(0-10$ e $10-$ 60) (dados não apresentados).

Assim, os extratos proteicos de plantas de amendoim não afetaram a eficiência de infecção dos J2. Os resultados obtidos apresentam correlação com aqueles observados por Guimarães et al. (2003), que detectaram a presença de fêmeas inférteis do nematoide, indicando não ter havido impedimento da entrada de $\mathrm{J} 2$ em raízes de plantas de amendoim, mas sim ao seu desenvolvimento. Essa característica indica não haver barreira física responsável pela resistência da planta a $M$. enterolobii, e sim que, algum componente expresso pela própria planta atua como o responsável pela inibição do seu desenvolvimento nas raízes.

\section{CONCLUSÕES}

O extrato proteico total de raízes de plantas de amendoim inoculadas com M. enterolobii não tem efeito sobre o desenvolvimento, a capacidade infectiva nem sobre a atividade de enzimas proteolíticas dos J2. Por isso, estudos dessa natureza com outras espécies resistentes ao patógeno, visando à identificação de proteínas que apresentem potencial para controle do nematóide, são necessários .

\section{AGRADECIMENTOS}

À FACEPE, ao CNPq e à Embrapa Semiárido, pelo suporte financeiro; aos colegas Jonas Enrique Aguilar Perales e André Teixeira da S. Ferreira, da FIOCRUZ, pela colaboração.

\section{REFERÊNCIAS}

Almeida EJ, Santos JM, \& Martins, ABG (2009) Resistência de goiabeiras e araçazeiros a Meloidogyne mayaguensis. Pesquisa Agropecuária Brasileira, 44:421-423.
Baermann G (1917) Eine einfache methode zur auffindung von ankvlostomum (Nematoden) larven in erdproben. Tijdschr. Ned.Indië, 57:131-137.

Bellafiore S, Shen Z, Rosso MN, Abad P, Shih P \& Briggs SP (2008) Direct identification of the Meloidogyne incognita secretome reveals proteins with host cell reprogramming potential. PLoS Pathog, 4:10.

Bradford MM (1976) A rapid and sensive method for the quantitation of microgram quantities of protein utilizing the principle of protein-dye binding. Analytical Biochemistry, 72:248-254.

Carneiro RMDG, Moreira WA, Almeida MRA \& Gomes ACMM (2001) Primeiro registro de Meloidogyne mayaguensis em goiabeira no Brasil. Nematologia Brasileira, 25:223-228.

Coolen WA \& D'Herde CJ (1972) A method for the quantitative extraction of nematodes from plant tissue. State Agricultural Research Centre, Ghent. 77p.

Good JM (1968) Management of plant parasitic nematode populations. In: Smart Jr G C \& Perry VG (Eds.) Tropical Nematology. Univ. Fla. Press, Gainsville, p.113-138.

Guimarães LM, Moura RM \& Pedrosa EMR (2003) Parasitismo de Meloidogyne mayaguensis em diferentes espécies botânicas. Nematologia Brasileira, 27:139-145.

Halbrendt JM, Lamondia JA (2004) Crop rotation and other cultural pratices. In: Chen ZX, Chen SY, Dickson DW (Eds.). Nematology: advances and perspectives, vol.2, Nematode Management and Utilization. Wallingford: CABI:Tsinghua University, p.909-930.

Laemmli LI (1970) Cleavage of structural proteins during assembly of the head of bacteriophage. Nature, 227:680-685.

Noe JP (1998) Crop and nematode-management systems. In: Barker KR, Pederson GA, Windham GL (Eds.). Plant and Nematode Interactions. Amer, Soc. of Agron., Inc., Madison, Wisconsin, p.159-171.

Ribeiro JM, Pinto M ST, Oliveira EAG, Castro JMC, Fernandes KVS, Ferreira ATS, Aguilar JEP \& Melo NF (2012) Identificação de uma lectina induzida pela infecção por Meloidogyne enterolobii em amendoim. Petrolina: Embrapa Semiárido. 15p. (Embrapa Semiárido. Boletim de Pesquisa e Desenvolvimento, 96).

Tunga R, Shrivastava B \& Banerjee R (2003) Purification and characterization of a protease from solid state cultures of Aspergillus parasiticus. Process Biochemistry, 38:1553-1558. 